\title{
Trash Teachings: How a Materials Science Module Series about Waste can Empower Engineering Students to be More Sociotechnically Responsible
}

\section{Dr. Breanne Przestrzelski, University of San Diego}

Bre Przestrzelski, $\mathrm{PhD}$, is a post-doctoral research associate in the General Engineering department in the Shiley-Marcos School of Engineering, where she innovatively integrates social justice, humanitarian advancement, and peace into the traditional engineering curriculum.

Before joining USD in August 2017, Bre spent 9 years at Clemson University, where she was a three-time graduate of the bioengineering program (BS, MS, and $\mathrm{PhD}$ ), founder of The Design \& Entrepreneurship Network (DEN), and Division I rower. In her spare time, Bre teaches design thinking workshops for higher education faculty/administrators at the Stanford d.School as a University Innovation Fellow, coaches a global community of learners through IDEO U, and fails miserably at cooking.

\section{Dr. Susan M. Lord, University of San Diego}

Susan M. Lord received a B.S. from Cornell University and the M.S. and Ph.D. from Stanford University. She is currently Professor and Chair of Integrated Engineering at the University of San Diego. Her teaching and research interests include inclusive pedagogies, electronics, optoelectronics, materials science, first year engineering courses, feminist and liberative pedagogies, engineering student persistence, and student autonomy. Her research has been sponsored by the National Science Foundation (NSF). Dr. Lord is a fellow of the ASEE and IEEE and is active in the engineering education community including serving as General Co-Chair of the 2006 Frontiers in Education (FIE) Conference, on the FIE Steering Committee, and as President of the IEEE Education Society for 2009-2010. She is an Associate Editor of the IEEE Transactions on Education. She and her coauthors were awarded the 2011 Wickenden Award for the best paper in the Journal of Engineering Education and the 2011 and 2015 Best Paper Awards for the IEEE Transactions on Education. In Spring 2012, Dr. Lord spent a sabbatical at Southeast University in Nanjing, China teaching and doing research.

\section{Prof. Michelle M. Camacho, University of San Diego}

Michelle M. Camacho is Professor of Sociology at the University of San Diego. She began her career at UC San Diego in 1999 as a postdoctoral fellow at the Center for US Mexican Studies, and later as a UC Faculty Fellow in Ethnic Studies. In 2015-16, she returned to UC San Diego as a fellow of the American Council on Education. As a bilingual/bicultural Latina, Camacho has 30 years of experience in higher education advocating for underrepresented groups and first generation college students. For over a decade, her work on institutional transformation has received funding from the National Science Foundation to examine and address inequities in higher education, specifically as they relate to Science, Technology, Engineering and Mathematics (STEM). She served the NSF ADVANCE grant initiatives as a co-Principal Investigator, working to improve practices to recruit and retain women of color in STEM and enhance institutional climate at USD. Other current research grants support pathways for veterans in higher education, and the NSF program called, "Revolutionizing Engineering \& Computer Science Departments." Her co-authored books include The Borderlands of Education (with Susan Lord), Mentoring Faculty of Color, and Beginning a Career in Academia: A Guide for Graduate Students of Color. She is past-Vice President (2017) of the Pacific Sociological Association, and an appointed consultant to the American Sociological Association's Departmental Resources Group. Fluent in both quantitative and qualitative research methodologies, her research uses theories from interdisciplinary sources including cultural studies, critical race, gender and feminist theories. Central to her work are questions of culture, power and inequality. She is affiliated faculty with the Department of Ethnic Studies, Women's and Gender Studies, and Latin American Studies. 


\title{
Trash Teachings: How a materials science module series about waste can empower engineering students to be more sociotechnically responsible
}

\begin{abstract}
There are growing industry demands for engineers to obtain a background in both technical skills and understanding social/global impacts. In a third-year Materials Science course at the University of San Diego, a module series introduced the responsibility of engineers to consider the life cycle of the products/processes they design. The course-long module series can be divided into four stand-alone modules that build on each other. The first module required students to bring to class with them a week's worth of their own trash to discuss the impact their personal waste contribution has on a regional scale. This module was enhanced based on student and instructor feedback from a first implementation offered in Fall 2017. This second module took students to a city-wide recycling processing center to observe the sorting processes that materials undergo once they are discarded. Through this field trip, students were able to recognize some of the challenges of current waste disposal and recycling practices. The third module welcomed a guest expert to share experiences with the global impact of waste disposal and the relative privileges that persist in developed countries. The fourth module asked students to critically assess materials for use in a commercial product, inspired by the regional and global challenges they were previously exposed to in the course. Following each activity, students completed a reflective assessment to track their understanding of the impact that their future engineering roles might play. From the compiled results, the student response to the modules was positive, leaving many students empowered, curious, and excited. The module series accomplished the goal of helping students be more prepared in understanding their role in designing materials with their end-use in mind, thus infusing technical and social engineering skill sets.
\end{abstract}

\section{Introduction}

Traditionally, the engineering canon focuses solely on technical skills; but there is growing industry and academic demand for engineers who design solutions with "sociotechnical" perspectives [1-4]. The term "sociotechnical" blends the social impact of technical engineering principles; it is a concept becoming increasingly common in the engineering education field. The field of Science and Technology studies has explored these interconnections for years. Thought leaders Baillie and Vanasupa design contextualized concepts for materials science students that introduce materials characterization, semiconductors, polymers, composites, and other common material science topics [5]. Others seek to bring sustainable engineering practices into the materials science classroom with short modules over the semester, a model much like those presented in greater detail in this paper [6]. Some develop full courses that blend technology in materials science with ethics and social responsibility [7-9].

The integration of the social and technical is also valued by ABET, requiring consideration of social and global impact in the engineering classroom [10]. This integration is one that has been underway at the University of San Diego Shiley-Marcos School of Engineering for several years. Supported by an NSF- funded Revolutionizing Engineering Departments (RED) grant, the larger 
goal of this work is to empower student engineering changemakers and develop sociotechnical content that faculty can incorporate into their classrooms [11-19].

The purpose of this paper is to describe the introduction and student/instructor response of four creative social context modules that together form a larger module series incorporated into a traditional materials science course. Each of the four modules address the topic of material waste, a global problem that is growing at a faster rate than urbanization itself [20]. Students first explored this area from a problem lens before they were invited to explore it from a solution lens. By the conclusion of the module series, students were asked to redesign products to lessen the impact on the global material waste crisis.

\section{Overarching Module Arc}

Four modules were designed to achieve the learning objectives shown below and comprised an arc as shown in Table 1. These modules were implemented in Fall 2018 in a third-year Engineering Materials Science required course throughout a 15-week semester. Eight students were enrolled: five Integrated Engineering majors, two Mechanical Engineering majors and one Industrial and Systems Engineering major.

The four modules were intentionally designed to achieve the following learning objectives.

1. Evaluate your own personal contribution to the global waste problem.

2. Compare waste generation in the USA and at least two other countries.

3. Describe at least three psychological factors that research shows influence recycling behavior.

4. Describe what is meant by "design for the dump" and why it may be problematic.

5. Consider a range of criteria including technical and social in choosing a material for a given design.

6. Describe why it is important for engineers to consider aspects of materials beyond measurable properties such as sustainability and human responsibility.

In the table below, the above learning objectives are mapped alongside the module designed to achieve it.

Table 1: Semester Arc of Modules

\begin{tabular}{|c|c|c|c|}
\hline Oct 17 & Nov 8 & Nov 16 & Dec 3 \\
\hline Bring in Your Trash & $\begin{array}{c}\text { Recycling } \\
\text { Processing Center } \\
\text { Tour }\end{array}$ & $\begin{array}{c}\text { Waste For Life with } \\
\text { Caroline Baillie }\end{array}$ & $\begin{array}{c}\text { Responsible Material } \\
\text { Design }\end{array}$ \\
\hline $\begin{array}{c}\text { What is your } \\
\text { contribution? }\end{array}$ & $\begin{array}{c}\text { Why is this so } \\
\text { tough? }\end{array}$ & What is the impact? & $\begin{array}{c}\text { Engineers taking } \\
\text { action }\end{array}$ \\
\hline LO 1,6 & LO 1,3 & LO 2, 4,6 & LO 5, 6 \\
\hline
\end{tabular}


The instructors included the instructor of record of the class who has expertise in Materials Science, Electrical Engineering, and Engineering Education research and a postdoctoral scholar with expertise in Bioengineering and Design Thinking. Both frequently use active learning techniques. In designing these modules, the instructors built on some of their lessons learned in designing modules for engineering students to introduce sociotechnical content. Specifically, the modules were designed so that they were an integral part of the class rather than an "add-on". Thus, assignments were incorporated into weekly homework assignments. Students worked in cooperative learning homework teams throughout the semester and for these assignments. All modules included some homework problems as well as an in-class activity or discussion. To assess student responses, a Google form electronic survey was administered after each module. This paper focuses on analyses of these responses including students' emotional responses and beliefs about how this content impacts them as engineers. Instructors' responses are also shared including reflection on preparing the exams for this course.

\section{Module 1: "Bring in Your Trash"}

The "Bring in Your Trash" module was incorporated into week seven of a 15-week semester. This module is the only module of the four described in this paper that has been previously implemented in this course. The first iteration of the module is described in detail in [15].

The assignment given to the students as part (20\%) of the weekly homework assignment was:

For class on Wednesday October 17, please bring in your trash for the week--use the bag that was provided to you. Do not change your habits- only add that which you would be normally throwing away. *Please no perishable items (i.e. bananas) or identifying information (i.e. bills).

a) Calculate each team member's individual waste disposal for the week [lb/day]

b) Calculate the average waste disposal per person per day for your group [lb/day]

c) Using the below reference, compare your team's average daily waste disposal to that of:

i. $\quad$ San Diego County and the state of California

ii. $\quad$ Your San Diego County Jurisdictions (where each member of your team lives) Reference: https://energycenter.org/equinox/dashboard/landfill-waste-disposal

Upon their return to class with their homework and trash bags, students were introduced to the large project grant. Following IRB protocol, they were informed of their potential roles and rights should they choose to engage as participants in the research, as well as their option to not participate. All students elected to serve as participants. Subsequently, they were invited to sign an informed consent form for both their participation in the research and consent for photographs to be taken in-class during the semester.

Significant data from the Center for Sustainable Energy was shared to introduce the local and regional need for exploration of this topic. Student teams were then guided through a trash sorting exercise that had students break down "complex" objects found in their trash. Complex 
objects included those that were comprised of at least two different materials. Students completed worksheet packets (see Appendices) as a team for approximately 25 minutes of the 55-minute class period. The remainder of the class period was spent discussing the process with guiding questions like: "What objects were easiest/most difficult to classify? What made these objects easy or difficult?" and "What makes a material recyclable?" and "How much of what we were going to throw away this week could have been (and still can be) recycled?" and "Why do/don't you recycle?" This discussion led to the instructors sharing three examples of communities that are prioritizing this waste problem in unique ways, from tribes using trash as ornamental decoration, to cities striving for a zero waste footprint, to non-profits only using recycled materials for their products. These examples set the stage for the final conversation around the question, "why should we, as engineers, be concerned about recycling of materials?" The class period concluded with student volunteers that stayed behind to assist in final trash/recycle sorting and cleaning of the space.

\section{Student Response}

Eight students attended class and brought their trash bags and completed homework assignments. Some students were unable to weigh their bags before class, so they weighed them in class. Each team's average weights were calculated and displayed on a classroom whiteboard and can be seen in Table 2:

Table 2: Student-calculated waste contribution based on the trash they collected over the week prior to the in-class module.

\begin{tabular}{|c|c|c|c|}
\hline & Team 1 & Team 2 & Team 3 \\
\hline $\begin{array}{c}\text { Average Waste Contribution } \\
{[\mathrm{lbs} / \text { day }]}\end{array}$ & 0.419 & 0.405 & 0.577 \\
\hline
\end{tabular}

Once teams calculated their individual and team waste contributions, an instructor-led discussion compared their daily contributions to those at the San Diego County and State level. Students were guided through a team trash sorting exercise, where they explored the contents of a collection of trash bags from those brought to class (did not have to be their own trash). An excerpt of one team's worksheet is shown in Figure 1.

The example in Figure 1 illustrates that most responses were brief and not very technical. One instructor reflected after the class, "I wonder what the effect on their table detail/accuracy would be if we allowed students the ability to look things up on their phones/laptops during class." Once student teams completed their trash sort, an ensuing discussion led students to examine the reasons why completing their tables was difficult at times. One student contributed, "We don't really know what materials things were." This led to a more detailed conversation about visual identification of materials but more accurate experimental testing. 

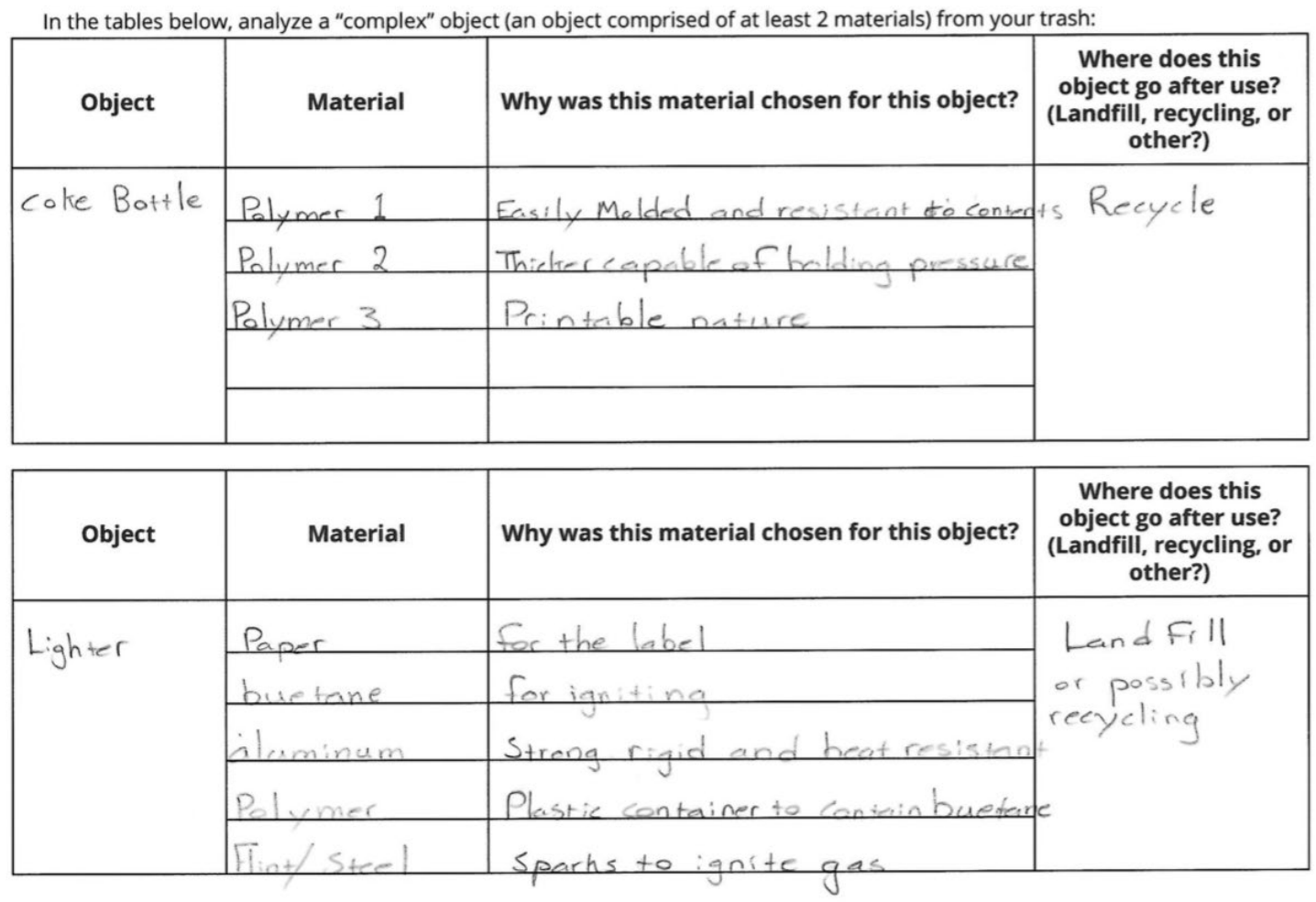

\section{䟱University of San Diego}

Figure 1: Example of student work during Module 1.

The instructor invited the student teams to share where the majority of their objects were destined (ex: landfill), and the objects explored were split evenly between landfill and recycling. However, when asked how many of the students regularly recycle, only 3 of the $7(43 \%)$ students raised their hands. This was surprising to the teaching team and was revisited later to assess how student interactions with the ensuing modules affected this answer.

Finally, the students were asked to reflect in pairs about what all of these objects have in common. One student responded, "Engineers created and formed the plastics." This led to an intended discussion surrounding engineering responsibility in this field; the objective was to initiate an introduction to be built upon in modules.

Seven students completed the post-class Google survey, submitting their responses between two to thirteen days after the in-class module. Submission time did not appear to have an effect on the responses. Table 3 shows responses to the question "When we discussed the materials we use and contribute to waste and recycling, I felt (click all that apply)" with the options being: "empowered", “depressed", "bored", "angry”, "drained", “excited", “curious", or "other" where students could write in their own response. Students were able to select more than one option and most (4/7) students selected at least two emotions. The two most common emotions selected were "empowered" and "curious" with no student selecting "angry" or "drained" but one student selecting "depressed" and another selecting "bored". One student did write in as "other": "A little sad about how much is going to landfill but not enough to call it depressed." It is important to assess these emotions as we aim to not leave the students feeling helpless. One other student 
selected "other" to represent the following: "wonder what I can do to change". Looking at all of the expressed emotions, $8 / 11$ (73\%) were positive while 3/11 (27\%) were not.

Table 3: Student Responses to "when we discussed the materials we use and contribute to waste and recycling, I felt (click all that apply)"

\begin{tabular}{|l|c|}
\hline Emotion Options & Number of student responses \\
\hline Empowered & 3 \\
\hline Depressed & 1 \\
\hline Bored & 1 \\
\hline Angry & 0 \\
\hline Drained & 0 \\
\hline Excited & 1 \\
\hline Curious & 3 \\
\hline Other* & 2 \\
\hline
\end{tabular}

Addressing another topic, Table 4 shows responses to the question "When we discussed the role that future engineers might play in waste and recycling, I felt (click all that apply)" with the options being the same as those presented above. Students were able to select more than one option and only two students selected more than one emotion. The two most common emotions selected were "curious" and "empowered" with no student selecting "depressed", "angry", or "drained", but one student selecting "bored". One student did write in as "other": "Neutral, I didn't feel extremely invested in the challenge. Maybe it's because I couldn't relate directly to specific actions that I could take now to have an impact. It felt like a very lofty future." It should be noted that this student was the same student who selected "bored" in the above table and also commented that what stood out to them about the class was that it "reminded me of an elementary school level survey of recycling."

Table 4: Student Responses to "when we discussed the role that future engineers might play in waste and recycling, I felt (click all that apply)"

\begin{tabular}{|l|c|}
\hline Emotion Options & Number of student responses \\
\hline Empowered & 3 \\
\hline Depressed & 0 \\
\hline Bored & 1 \\
\hline Angry & 0 \\
\hline Drained & 0 \\
\hline Excited & 2 \\
\hline Curious & 4 \\
\hline Other & 1 \\
\hline
\end{tabular}

Looking at all of the expressed emotions, 9/11 (82\%) were positive while 1/11 (9\%) were slightly more negative ("bored") and 1/11 (9\%) were neutral.

Students were asked to reflect on what stood out to them about the class itself. Two students commented on the increased awareness of the waste/recycling problem (e.g.: "Becoming more conscious of out [sic] impact on the world"), while two others were astounded by the "amount of food boxes" and "amount of trash used per day in San Diego". One expressed surprise at the 
process itself: "It was really interesting to learn that many things we try to recycle, if it is not fully recyclable, the center will not sort it but simply send the whole item to the landfill."

Several students expressed appreciation for the change of tempo of class (e.g. "I liked the way it was a tangible/out of class experience.") and actually requested the module take place outside of the normal class period and take longer "so I could focus more on the activity." A few others commented on the reality their own trash brought to the activity (e.g.: "It was cool to do it with our own trash because it made it much more applicable!")

Students then reflected on how this class helped them to better understand their roles as engineers who design materials with their end use in mind. Most students (71\%) described specific design factors they might now be more aware of, such as "incorporat[ion of] used materials into innovation", "biodegradable materials", "find[ing] materials to use that can be easily recycled and reused, or to use these recycled materials", "materials that are environmentally friendly and sustainable", and finally "need[ing] to make objects that are easily recycled without sacrificing what the object needs to function." One student's perception about industry's priorities is an interesting point to further explore in later iterations: "Keeping end of life in mind is important but it likely won't be a primary consideration for most materials choices."

\section{Module 2: Recycling Processing Center Tour}

Students were informed of the upcoming recycling processing center tour at the conclusion of the previous module, but the precise date of the tour was not determined until a later time. Contact was made with several processing centers over many weeks, and final arrangements were made with EDCO, a family-owned and locally-operated waste collection and recycling company that serves many communities in the region [21].

Student teams were required to complete a homework assignment prior to visiting the recycling process center that challenged them to connect psychological concepts from a recycling news article to their observations from the trash class, and also prepare compelling questions for the tour. The four questions from the assignment (30\% of the assignment) are below:

Read this CNN article (5-minute read) on the psychology of recycling: https://www.cnn.com/2017/05/18/health/psychology-of-recycling/index.html

In this article, several psychological factors that contribute to recycling were introduced.

a) Describe 4 of these factors in at least one sentence per factor

b) Pick one factor and describe in at least one sentence how it could be considered in the engineering design phase of a consumable product.

c) Describe what is meant by an "affordance" and how the author says it is relevant to recycling. (You might remember this term from ENGR 103).

d) Before Fall Break, you examined what you and your classmates throw away. After reading this article, what might have contributed to why the objects you saw in the trash were there? Please refer to specific objects in your trash and information from this article. 
e) We will be visiting a waste disposal/recycling center. Compile at least 5 unique, compelling questions to ask those who will be giving us the tour.

The visit to the waste disposal center was held in early November during the tenth week of the semester. Four students attended the visit and were invited to reflect on their experience using the post-tour Google survey. The facility was about 30 miles away and took about an hour of driving given traffic conditions on the day and time of the tour. For those students who were unable to attend the tour in-person, a video link introducing the EDCO facility was provided so that these students could complete an alternate Google survey that asked content questions related to the video as well as module reflections.

\section{Student Response}

Each student homework team completed their pre-EDCO tour homework assignment, preparing them for the EDCO processing center tour. All teams provided at least four physiological factors that contribute to recycling that were referenced in the article. Most teams chose to manipulate the social norms/material branding factor to increase recyclability of an engineered product while others acknowledged the role of the designer, engineer, and manufacturer of the product including the material properties (more sturdy materials to prevent physical damage, which contributes to heightened trashing of recyclable products). Each team correctly defined "affordances". When asked to directly apply these factors to what was brought in their trash to class, two teams acknowledged lack of pro-recycling social norms in their communities (e.g.: "lack of recycling bins in the dorms" and "recycling may not have been a social norm in the individual's house"). One team communicated direct connection from the article to their observation during the "Bring in Your Trash" module: "[T] he reason they [food containers] were in the trash is due to the fact that there were some food remnants still in the containers and due to this fact, they were not recycled. We believed the items were too dirty or damaged to be recycled when it reality they still could have been recycled."

Lastly, students compiled potential questions to ask the EDCO tour guides. Questions ranged in level of depth, from basic procedure/process questions (e.g.: "How do they organize the material if someone recycles something poorly and puts things that don't go together in the bin together?" and "How much of a recycled object is recyclable? All of it or just a portion?" and "What is the most valuable recycling material and what is it used for?") to those inquiring about their engineering role in a problem definition (e.g.: "How do you think the recycling process could be made better?" and "What are some reasons you think people don't recycle more?") and finally those inviting employee reflection (e.g.: Do you think working at a recycling center has caused you to be more considerate of what you throw in the trash?"). The next iteration of this module might involve revisiting these questions after the EDCO tour to see how many they can answer now and also, what new/different questions they might have.

While all student teams prepared questions for their attendance at the EDCO center, only four students were able to attend the tour. Contributing to the low attendance was the center's distance from campus, the time of day, class conflicts, and two students feeling sick on the day of the tour. The students completed their respective surveys-- four students completed the posttour Google survey and three students completed the post-EDCO video Google survey. 
Students submitted their responses between one to eighteen days after the tour. Submission time did not appear to have an effect on the responses. Table 5 shows responses to the question "When we discussed the materials we use and contribute to waste and recycling, I felt (click all that apply)" or for those who were unable to attend the tour, the question "When I saw the materials we use and contribute to waste and recycling, I felt (click all that apply)". The options for both sets of questions were the same as those introduced before: "empowered", "depressed", "bored", "angry", "drained", "excited", "curious", or "other". Students were able to select more than one option and only one student selected more than one emotion (one of the four students that completed the post-tour survey). All of the students who completed the post-EDCO video survey selected "curious" as did three (75\%) of the students who completed the post-tour survey, making it the most common emotion selected. No student wrote in an "other" response. One student only selected "depressed" while the other student who selected a negative emotion ("angry") also selected "empowered" and "curious". This might suggest that the emotions experienced during the tour were complex and worthy of further exploration, possibly later in class.

Table 5: Student Responses to "when we discussed/saw the materials we use and contribute to waste and recycling, I felt (click all that apply)"

\begin{tabular}{|l|c|c|}
\hline & \multicolumn{2}{|c|}{ Number of student responses } \\
\hline Emotion Options & Post-tour & Post-video \\
\hline Empowered & 1 & 0 \\
\hline Depressed & 1 & 0 \\
\hline Bored & 0 & 0 \\
\hline Angry & 1 & 0 \\
\hline Drained & 0 & 0 \\
\hline Excited & 0 & 0 \\
\hline Curious & 3 & 3 \\
\hline Other & 0 & 0 \\
\hline
\end{tabular}

Looking at all of the expressed emotions, $7 / 9(78 \%)$ were positive while $2 / 9(22 \%)$ were not.

Table 6 shows responses to the question "Now reflecting on the role that future engineers might play in waste and recycling, I felt (click all that apply)" with the options being the same as those presented above. Two students selected more than one emotion, one student on each survey. The most common emotion expressed on the post-tour survey was "excited" and on the postEDCO video survey, the most common emotion was "empowered". Two students selected "other", one student on each survey. The student who attended the tour contributed "responsible" and the student who watched the EDCO video contributed "depending on the kind of job I get, or where I decide to go in the engineering field this might affect me a lot, or not much." The former suggests a powerful emotion that the authors might include in subsequent surveys, while the later suggests an opportunity to visit the perception that these concepts do not affect all divisions of an industry. 
Table 6: Student Responses to "Now reflecting on the role that future engineers might play in waste and recycling, I felt (click all that apply)"

\begin{tabular}{|l|c|c|}
\hline & \multicolumn{2}{|c|}{ Number of student responses } \\
\hline Emotion Options & Post-tour & Post-video \\
\hline Empowered & 1 & 2 \\
\hline Depressed & 0 & 0 \\
\hline Bored & 0 & 0 \\
\hline Angry & 0 & 0 \\
\hline Drained & 1 & 0 \\
\hline Excited & 2 & 1 \\
\hline Curious & 0 & 0 \\
\hline Other & 1 & 1 \\
\hline
\end{tabular}

Looking at all of the expressed emotions, $7 / 9(78 \%)$ were positive while $1 / 9(11 \%)$ were not, and $1 / 9(11 \%)$ were neutral.

Students were asked to reflect on what stood out to them about the EDCO tour. Most (75\%) of the students referenced the process as a whole (e.g. "The amount of people that worked in the process doing all the jobs, the height, size and structure of the machines and how there were a lot of different processes that the materials went through to separate the different types") and/or specific functions within that process (e.g. "The optical laser that they use to sort the recycling down was interesting, and how much it helps to sort the trash beyond even what humans can do." Or, "how the countries require a minimum amount of contamination and will not accept it if it is over the limit").

Three students also commented on their surprise at the amount of waste and processed material (e.g. "it was very impressive to see the giant pile of trash that needed to be recycled, and he [tour guide] said it was only after 5 hours of collection."). One student left the tour curious with more questions: "The economics of the facility were still a bit mysterious even after the trip. Do we pay for them to collect our material after which they sort and sell it? How does that work? I'm curious to see how successful this facility is compared to a different kind of program in Europe that demands a high level of sorting" It is promising to see that for at least one student, this tour left them curious about content they would not normally have been exposed to and asking questions that might lead to future interest.

All students who watched the EDCO video correctly answered the first two questions that came directly from the content of the video (Answers: (1) 64 million single-use beverage containers and (2) 100,000 pounds of co-mingled recycling). These three students also described in one paragraph how material classification/properties played a role in the EDCO materials sorting process, and it was clear from their responses that each saw the connection between material classification/properties and the recycling sorting process (e.g. "Material classification and properties play a large process in the material sorting process. The different properties of the materials allow for sorting to happen at all. The steel and tin are magnetic, allowing them to be separated using magnets while the rest of it goes on. How brittle an object is also plays a part as glass is broken and separated from less brittle objects and sent to its own cleaning line."). This 
points to potential use of this video in place of a tour, especially in locations where centers are unable to provide tours or timing of facilities does not work with the class schedule.

Both groups of students described how the tour/video helped them to better understand their role in designing materials with their end use in mind. Many students were fairly general in their responses (e.g. "Knowing what is actually done with these materials instead of simply saying they're going to be 'recycled' will help my design process considerably. Knowing which materials are more beneficial or more easily recycled can help drive my materials and design choices.") while three students named specific areas or materials to use for process improvement (e.g. "We need to not only find and utilize materials which are compostable but also aggressively cut out the uses of non-recyclable material from all manufacturing processes"). It is promising to see that both groups of students could reflect on how this content could impact their future engineering careers.

Students were invited to leave final comments. One student who attended the tour shared, "Already it has made me more conscious of the materials and products I use everyday, and it really sparked my interest in getting more involved in recycling and the whole process". One student who was unable to attend the tour, but rather just watched the video shared, "These are some pretty cool activities. I would love to have a project to help apply some of these ideas and to start more critically on how we could create or recreate products so they could be more easily flow into the recycling project. Maybe we could design and launch an imaginary object.". These comments reflect the openness to this content by the students and highlight the desire for this type of application-based content in the classroom-- when students are asking for more work, as is the case in the later comment, something about the topic is truly resonating with them.

\section{Module 3: Waste For Life with Caroline Baillie}

This module was incorporated during week 11 of the 15 -week semester. Caroline Baillie, $\mathrm{PhD}$, a materials engineer and thought leader in reducing global waste, was invited to lead an interactive hour with the class about her organization Waste For Life, a network of leaders working "to develop poverty-reducing solutions to specific environmental problems" [22].

Prior to Dr. Baillie's visit to class, the student's weekly homework assignment $(40 \%$ of this assignment) included two problems related to this module.

On Friday November 16, 2018, Dr. Caroline Baillie will be leading our class in a module on "Waste: A Global Problem and Opportunity". In preparation for this, please complete problems 6 and 7.

1) Reference: World Bank Global Review of Solid Waste Management (http://documents.worldbank.org/curated/en/302341468126264791/pdf/68135REVISED-What-a-Waste-2012-Final-updated.pdf). Use the Abbreviations and Acronyms (page xi), the Country Classification According to Region (page xii), and the Country Classification According to Income (page xiii) for the following questions. 
This World Bank report describes municipal solid (MSW) waste generation, collection, composition, and disposal as it varies by region and income.

1. Describe how the USA (in the OECD region) compares in its waste generation to at least two other regions. Refer to Table 3, Figure 1, Table 4, and the embedded text. Include data (consider using a table) and words to explain the comparison.

2. Describe how the USA (in the High Income Level region) compares in its waste generation to at least one other income level. Refer to Table 5, Figure 2, Table 6, and the embedded text. Include data (consider using a table) and words to explain the comparison.

3. How does the above average $\mathrm{kg} / \mathrm{capita} /$ day compare to that which you and your team generated in one week for the "Bring in Your Trash" module?

4. Reflect on what the above data might mean for a future engineer looking to produce materials for consumption.

2) Please read through one of Dr. Baillie's papers [23]:

a) From the data presented in Figure 5 for Tensile strength versus fibre content and Figure 6 Modulus versus fibre content, what do you think is the optimal fibre content for strength and modulus in these samples? Include the values of tensile strength and modulus expected. Explain your reasoning.

b) What is complicated about this data?

In class, Dr. Baillie highlighted through guided discussion the global impact of the problem, how waste disposal relates to socioeconomic status, the Western World privilege with waste, and what is currently being done to address this global problem.

\section{Student Response}

All student homework teams completed their homework assignment, preparing them for the guest lecture given by the expert on global and social responsible waste disposal. Each team was able to successfully compare and contrast the values from their own daily waste generation to those presented in the World Bank Global Review of Solid Waste Management. However, all teams experienced challenges in analyzing the banana fiber data that was provided to them. Given the complexity of the real-world data, this is not surprising.

Five students completed the post-class Google survey, submitting their responses between two to eleven days after the in-class module. Submission time did not appear to have an effect on the responses. Table 7 shows responses to the question "When I saw the materials we use and contribute to waste and recycling globally, I felt (click all that apply)" with the options being those displayed in the table below. Only two students selected more than one emotion. The two most common given emotions selected were "empowered" and "curious" with one student selecting both "angry" and "drained", but none selecting "depressed" or "bored". Two students did write in as "other": "interested" and "intrigued", two seemingly positive emotions. 
Table 7: Student Responses to "when I saw the materials we use and contribute to waste and recycling globally, I felt (click all that apply)"

\begin{tabular}{|l|c|}
\hline Emotion Options & Number of student responses \\
\hline Empowered & 2 \\
\hline Depressed & 0 \\
\hline Bored & 0 \\
\hline Angry & 1 \\
\hline Drained & 1 \\
\hline Excited & 1 \\
\hline Curious & 2 \\
\hline Other & 2 \\
\hline
\end{tabular}

Looking at all of the expressed emotions, $7 / 9(78 \%)$ were positive while $2 / 9(22 \%)$ were not (both emotions coming from the same student).

Table 8 shows response to the question "Now reflecting on the role that future engineers might play in waste and recycling, I feel (click all that apply)". All but two students selected more than one emotion. Overwhelmingly, the students felt positively about this module with all five students selecting "empowered" and three students selecting "excited" and "curious".

Table 8: Student Responses to "now reflecting on the role that future engineers might play in waste and recycling, I feel (click all that apply)"

\begin{tabular}{|l|c|}
\hline Emotion Options & Number of student responses \\
\hline Empowered & 5 \\
\hline Depressed & 0 \\
\hline Bored & 0 \\
\hline Angry & 0 \\
\hline Drained & 0 \\
\hline Excited & 3 \\
\hline Curious & 3 \\
\hline Other & 0 \\
\hline
\end{tabular}

All of the expressed emotions 11/11 (100\%) were positive.

Students reflected on what stood out to them about the talk given in class. Several students commented on the magnitude of the global issue (e.g. "how much waste is exported outside of our country" and "learning about the landfill in Sri Lanka that collapsed and caused multiple deaths was shocking. It really illustrated the magnitude of the problem and how much the issue is ignored on a big scale.") while others recognized the expert's passion for solving this global issue (e,g, "Her persistence in educating an extremely ignorant world on the problems of material waste abuse"). One student expressed now seeing opportunity: "It rang of future economic opportunities. I think the ability to recycle waste into a meaningful product will have a legitimate financial implication in the next few decades".

Students were also asked to share something about waste disposal and recycling processes in the USA and other countries that they would continue to remember after this class. Three of the five 
students stated that the scale and responsibility of the disposal challenges would stay with them (e.g. "We need to be considerate about waste tech materials and how we dispose of unusable products."). Another student found the complexity of the challenge most interesting: "It was interesting to learn that when cities or neighborhood try to clean their streets, the trash does not go away, but they just dump it somewhere else. It definitely showed the complexity of the issue and how there is not one easy solution". One student shared meaningfully, "I will remember that products made always have a life after they are thrown out".

When asked to describe how this module helped them better understand their roles in designing materials with their end use in mind, all of the students built on the content they found interesting in class and some even claimed responsibility (e.g. "It is our duty as inventors/innovators to be producing but also protecting our planet."). One student in particular applied their learnings beyond that of traditional materials to that of the software industry, communicating advanced application of this content: "I am planning on working in the software industry, and while a lot of it is virtual, it made me think about creating software that works on multiple platforms and creating systems that do not become obsolete so quickly but finding ways to make them work for as long as possible."

Final comments that students left only further emphasized the desire for this type of applicationbased content in the classroom. Several students asked excitedly (e.g. "THIS WAS AWESOME AND I AM SO SO GLAD WE DID IT") for more of this content either in an entire class ("really cool; wish there was a class on this") or in a longer class period. One student that expressed an interest in a more lengthy class period did so to be able to more fully explore the content: "I wish we had more time to discuss it because we covered such big concepts but didn't have time to fully talk about it and debrief it. I think it's important to not just learn about it, but also talk about how we can just the information in a real way."

One student did feel that "the information regarding the developed world's larger contribution toward waste production is a bit overemphasized and has been for all the different modules. I think more emphasis on how products could be designed for reusability would be more beneficial and interesting." This final comment is important to consider in future module design to ensure the message communicated is one of action.

\section{Module 4: Responsible Material Design}

The final module in this series required students to combine their learnings from the previous three modules to produce a written memo and oral presentation as if they were a consultant for a new beverage company (Ambrosia ${ }^{\mathrm{TM}}$ ) aiming to decide what material to bottle their new beverage in. Student teams were assigned one of three companies to represent (Gaslamp Glass, Point Loma Polymers, and Alta Vista Aluminum) which manufactured one of three materials they were to gather for their memo and oral presentation content (soda lime glass, polyethylene teraphthalate (PETE), and aluminum). The module assignment was framed such that "the consultant group that Ambrosia feels best represents what they are seeking in a material for beverage containers will secure a long-term contract for beverage container manufacture." Although seemingly competitive, the assignment required all groups to deliver the following for 
their material, to maintain consistency but also ensure that student groups were being critical of their material and not only presenting the positives. Students were asked to consider:

A. The classification of the material

B. Material properties pertinent to beverage containment (ex: ductility, tensile strength) and values specific to the material of interest

C. The manufacturing process of the material (high-level overview)

D. The recycling process (or lack thereof) of the material (optional: include additional materials associated with the beverage container (ex: lid, label))

E. Uses of the recycled product and where unrecyclable product goes

F. Amount of the material used in the United States yearly and percent contribution to landfills

G. The cost of the material

H. A critical analysis of the pros and cons of the material if used for the beverage container

I. For each con, propose an engineering (technical, environmental, social, or economical) solution that might mitigate the risk associated with this material. (Think: what might a future engineer consider when facing these material limitations?)

The full assignment can be seen in the Appendices. Each student team was given at least three starting places from which they could begin their research. Students were given one week from module introduction to required delivery of presentation and memo, which occurred during week 13 of the 15 -week semester.

Student Response

All student homework teams prepared their memo as well as an in-class presentation. The level of depth of content varied across teams. Upon conclusion of the student presentations, an inclass instructor-led discussion ensued to determine which of the three materials seemed to be the "best" choice for the beverage container. Many questions organically surfaced from the students during this discussion, in topics areas such as sourcing of materials, social norms/standards associated with certain materials, transportation costs, environmental impact intention of the consulting company (Ambrosia ${ }^{\mathrm{TM}}$ ), taste contamination of the beverage, smells generated during the processing of the materials, beverage temperature preference, duration of time decomposing in landfills, and environmental policies. By the conclusion of the discussion, votes were cast for each material with the following distribution as shown in Table 9.

Table 9: Number of votes each material choice received

\begin{tabular}{|l|c|c|c|}
\hline & Glass & PETE & Aluminum \\
\hline Student votes & 2 & 0 & 5 \\
\hline
\end{tabular}

One unplanned addition to the class period was that of the arrival of material samples that drew excitement from the students. Following presentations, the instructor presented the class with several material samples of PETE in various forms found in the recycling process from the National Association for PET Container Resources (NAPCOR) [24]. These physical samples elevated the conversation and even led to one of the quieter students to rush out of the room 
excitedly to fill one of the material vials with water to see the PET separate from the caps and labels that float. These material samples will be an intentional inclusion in future classes.

None of the students completed the post-class Google survey. This was possibly due to survey fatigue as well as unfortunate alignment with another exam for this class later in the week as well as large assignments for other classes and upcoming final exams. After receiving no responses after sending several reminders, it was decided to collect a final round of feedback in-person with a focus group.

\section{Focus Group}

The social scientist on the RED grant conducted a focus group with these Material Science students during class in the penultimate week of the semester. Three findings were identified. 1) Mindset about waste; 2) Barriers to implementation; and 3) Variation in developmental preparation for content.

\section{Mindset about waste}

Student comments varied, but most concurred that the experience was valuable. For example, one woman student indicated, "we were taken out of the typical classroom setting [to analyze] materials like what our role as engineers [would be] if we were to use a material and how that's going to affect, not just us in the future, but countries globally." When the guest speaker came in, "I learned how [our trash] goes to wastelands in other countries. I thought our American trash was ours...I didn't realize our trash was going to other communities and destroying them." Another concurred and suggested that most engineers do not consider the "byproducts of what we're doing" because "we're creating and the only byproduct is the positive impact that our innovations have. I think that's just a cop-out now, and [there's] a whole other realm... It was just interesting to have one mindset that didn't incorporate anything in terms of waste, and now it seems like it the most impactful factor in all of engineering because it's so lasting and there permanently."

A critical comment about the modules suggested a need for more sustained attention or prolonged effort to the topic. Students lamented, "I have all this other work that I have to do, and then instead of trying to check off the box, you have to sit down and really think about the decisions you're making." Another student added, "[In] being mindful of the impact that our decisions as engineers make in regard to waste, I feel like you can't have something where it's just one time and then [not] think about it. ... You have to think, well waste is a problem, but how do I do something about it? ... You kind of open your mind to this whole different world that you didn't really think about. But now that you know that, what do you do?" As another student echoed, is "it's got to be a lifestyle and not just something you occasionally do in one class."

These comments suggest an openness toward new knowledge in the engineering curriculum. Just as one who becomes literate in reading will never unlearn that skill, so too do students recognize their newfound literacy about engineering and waste. 


\section{Resistance to implementation}

Some students shared concerns about some elements of depth and course design, such as "the restrictions you have when you're asking students to carry trash." Another said, "it wasn't as indepth as it was meant to be." Another concurred, "I think in a perfect world we would've had more time to do it; it would be great if they offered a class just on this, though realistically people wouldn't put in the work to do it. She [the instructor] had to test us on it so we would show up and do them, because we just wouldn't do it otherwise. And so, I think it could be better if we could dedicate all this time just to it." [Conversely,] "I need to get through this materials that I'm going to need for my career, so I think ... if there's a better way to do it, maybe yeah, just talking about it more as opposed to dedicating like big chunks, smaller chunks, I don't know."

Students expressed resistance for other reasons as well, suggesting, "there's not any big revelation... we know industrialized first-world nations produce more waste than other nations. We knew that coming here. We know recycling only includes some materials...everything was revealed like it was this big epiphany, like we had no idea; but it was just a waste of a day for the most part." Another student disagreed, "yeah, you know about it but that doesn't mean anybody cares... I'm more intentional with what I recycle now. I actually think about it." Another concurred, "I don't think the majority of us have been to a recycling plant like that, like the dump, in person like that. So, it...puts everything into perspective, like what we know in perspective."

Another perspective focused on control of the design process, “...Assume I'm an electrical engineering and I go into the design process thinking, 'man, I'm not going to design for the dump, I'm going to design for reusability, or remanufacture ability,' then the [boss might say], 'Oh this costs four times as much, you can't do that.' [Then] it's like 'Oh okay I guess I'm not doing that.... "You have very little control over what you do long-term unless you're striking out on your own and doing your own thing." Thus another layer to resistance seemed to suggest cynicism and a lack of individual power to make a difference as well as a limited understanding of and experience with actual engineering workplaces.

\section{Variation in interest, context, and preparation}

Students varied in their preparation for the waste modules. For example, one student disdainfully suggested that he learned nothing new, "the information is a review of stuff I learned in elementary school and high school." Another student said, "If I'm going to be honest, I think in my career it won't come into play that much, because a lot of [my future career] is coding and I'm going to use an already made computer, and I'm not actually making a physical product. Another added that other sections of this materials science class "that are mechanical engineering materials classes aren't learning about it. ... It should be the other professors who are teaching mechanical engineering who are talking, because it would just have much more of a direct impact." This more direct impact could be due to the larger enrollments in mechanical engineering.

One student offered a summarizing statement at the end of the focus group calling for more of this type of work. 
"We hear about being Changemakers and what does that mean? I think one of things we have to ask ourselves is, 'What do I value?' Because, right now, I think that the program doesn't reflect the value of changemaking because ... we want to become an engineer, which is an amazing thing, we want to become an engineer and we want to help innovate. But then, the value is placed on information and being able to problem solve .... the value isn't based on, 'How do I be a changemaker? How do I be mindful about my decisions?

How do I make do? How do I take the time to be environmentally friendly?' And I think that's missing. Because ... if you value something like that, then a sizable portion of the program, at least like 10 to $25 \%$, should be spent on the projects where you have to make those decisions, and you have to practice what you preach, you have to practice that way, 'Oh, I believe in being environmentally sustainable.' Well then that means you have to practice that."

The comment suggests a need for greater infusion of this topic in the engineering curriculum, and a greater focus on embedding these values into students' critical thinking.

\section{Bringing the modules' results together}

Following each of the first three modules, student responses to the following questions were captured. They are displayed in Table 10 and Table 11 to demonstrate the change (or lack thereof) in attitude toward this sociotechnical material throughout the semester.

Table 10 shows responses to the question "I think the topics we covered in BLANK module matter to me as an engineer" with Likert scaled student responses from 1-5, where 1 represents "does not matter at all" and 5 represents "matters a lot". The average values did not change drastically across the semester, with the lowest score being 3.75 following the EDCO tour. Surprisingly, the students who only watched the EDCO video felt more strongly than those who went on the tour. However, this may be due in part to the number of students who contributed to each survey ( 4 for the tour and 3 for the video) but also the inconvenience associated with the tour itself. The module that ranked the highest amongst these modules was that of Module 3.

Table 10: Average Student Responses to "I think the topics we covered in BLANK module matter to me as an engineer." where students could select a single value form 1-5 (where 1=does not matter at all and $5=$ matters $a$ lot)

\begin{tabular}{|l|c|c|c|c|}
\hline & $\begin{array}{c}\text { Module 1: } \\
\text { Bring in } \\
\text { Your Trash }\end{array}$ & $\begin{array}{c}\text { Module 2: Recycling } \\
\text { Processing Center } \\
\text { Tour (tour) }\end{array}$ & $\begin{array}{c}\text { Module 2: Recycling } \\
\text { Processing Center } \\
\text { Tour (video) }\end{array}$ & $\begin{array}{c}\text { Module 3: Waste } \\
\text { For Life with } \\
\text { Caroline Baillie }\end{array}$ \\
\hline Average & 4 & 3.75 & 4.33 & 4.6 \\
\hline
\end{tabular}

Table 11 shows responses to the question "This BLANK (class, tour, video, or module) helped me to better understand my role in designing materials with their end use in mind." with Likert scaled student responses from 1-5, where 1 represents "I strongly disagree" and 5 represents "I strongly agree". The average values did not change drastically across the semester, with the lowest score being 4 following the EDCO tour or video which is still "agree". Again, the module that ranked the highest amongst these modules was Module 3. 
Table 11: Average Student Responses to "This BLANK helped me to better understand my role in designing materials with their end use in mind." where students could select a single value form 1-5 (where $1=I$ strongly disagree and $5=I$ strongly agree)

\begin{tabular}{|l|c|c|c|c|}
\hline & $\begin{array}{c}\text { Module 1: } \\
\text { Bring in } \\
\text { Your Trash }\end{array}$ & $\begin{array}{c}\text { Module 2: Recycling } \\
\text { Processing Center } \\
\text { Tour (tour) }\end{array}$ & $\begin{array}{c}\text { Module 2: Recycling } \\
\text { Processing Center } \\
\text { Tour (video) }\end{array}$ & $\begin{array}{c}\text { Module 3: Waste } \\
\text { For Life with } \\
\text { Caroline Baillie }\end{array}$ \\
\hline Average & 4.14 & 4 & 4 & 4.6 \\
\hline
\end{tabular}

Reasons for student responses to the values selected in the Table 11 have been described in earlier sections. It is valuable to see this data reflected across a semester as it shows that while different modules covered different topics, some at greater depth than others, and some with greater shock factor impact, all modules clearly communicate to the students that this material is important to them as future engineers. It also shows that these modules better prepare them to challenge current industrial processes in their future roles when designing materials with their end use in mind.

\section{Instructor Reflection on Exams}

In preparing the exams for this course, the lead instructor was motivated to make more changes than she had done in years. For all exams after the first module, she aimed to include some larger context and items directly related to the modules' learning objectives. For example, on midterm 2, students were directly asked to compare the amount of their daily waste to that in San Diego county (LO1). Midterm 3 included a problem asking students to "describe two psychological factors that research shows encourage people to recycle" (LO3). Students did a good job although some gave answers that were not tied to the article they read for homework. The question will be clarified to specify this in the future. In addition, on midterm 3 , the instructor added broader considerations to a capacitor design problem where students have to choose a material for a capacitor and justify their choice. In previous years, students had been given data on materials' dielectric constant and dielectric strength. This year, cost and whether or not it was toxic was added to address LO5. All students chose a nontoxic material suggesting an awareness of the importance of criteria beyond the strictly technical.

For the final exam for 2018, the order of topics had changed in 2018 to ensure that students had covered polymers and ceramics before the final module. Thus some changes in emphasis were needed overall in the final exam in addition to incorporating items related to the modules' learning objectives. Initially, the instructor planned on asking a question addressing LO6 about why it is important to consider items beyond technical requirements in choosing a material. Fearing it might be too vague, she instead focused the question on a specific application discussed in class, designing a capacitor, asking what factors would be important to consider and why thus addressing both LO5 and 6 . The question on the exam was:

In an interview for a job at Exciting Engineering, the hiring manager asks you "I see that you took a materials science class. As an engineer, if you are choosing a material for a capacitor, besides the dielectric constant, what properties or factors do you think are most important to consider and why?" Please answer in complete English sentences. (describe at least 4 different factors or properties) 
Asking for four factors not including the dielectric constant, the most common technical consideration, required students to think deeply. Rather than asking for considerations beyond the technical, she (the instructor) hoped these might emerge authentically. Students did need to mention the technical consideration of dielectric strength as having a material with insufficient dielectric strength would be unacceptable. Six students did mention dielectric strength with four putting it first. All students listed some typical technical measurable considerations such as size. Five students mentioned an economic factor, cost or price. Six students mentioned a broader consideration including toxicity (3), recyclability/environmental impact (3), and sourcing (3). Recyclability is important to consider especially with electronics. As learned from "design for the dump", I want to make sure my product is safe and able to be recycled.

Environmentally designing for recycling can provide cost benefits long term. In Addition, as environmental concerns become more mainstream, there is a possibility of additional costs of taxes being leveraged on non-environmentally conscious manufacturers.

The instructor was pleased that both students who were in a previous class that had discussed conflict minerals and supply chains [19] mentioned sourcing and conflict minerals. Interestingly, both students put this as their fourth factor.

Source is a factor. As Exciting Engineers, I'd try to stay away from using materials mined in conflict areas (conflict materials).

The final factor to consider is where the material is mined from. Many materials used for capacitors can be considered "conflict minerals" because the mining practices around them are unjust. Even if it may be more expensive it is worth using an ethically sourced material.

Although it was more work to redesign many problems on the exams, the instructor thought it was worth it. If the learning objectives related to these modules and broader social considerations are included in the class discussions but only technical calculations are included on the exams, instructors send a message about what is really important and what is not. These modules help shape the students' perceptions of social considerations and also gives shape to content appropriate to meet the ABET social and global impact requirements.

\section{Conclusion}

Four modules emphasizing material environmental impact were successfully incorporated into a required third-year Material Science classroom. Students explored their own waste habits, comparing them to local, national, and global populations, and finally concluded the semester with a critical analysis of three material options for a product (beverage container). Student response to the modules was positive with students asking for more content like this in each survey conducted. In addition, the emotional response to the modules was for the majority positive, leaving students feeling empowered, curious, and excited. This module series has accomplished the goals of helping students be more prepared to understand their role in 
designing materials with their end use in mind and helping engineering faculty meet ABET impact requirements.

\section{Acknowledgements}

The authors would like to thank the students in the Materials Science class for their participation, the EDCO Materials Processing Center for their generosity in leading a tour of their facility, and Dr. Caroline Baillie for her contribution to the module content. The authors also acknowledge the support of the National Science Foundation through Grant 1519453.

\section{References}

[1] B. Cohen and K. Sanford, "Introducing Engineering as a Socio-technical Process," in Proc. 2014 ASEE Annual Conference \& Exposition, Indianapolis, IN, June 2014.

[2] National Academy of Engineering. The Engineer of 2020: Visions of Engineering in the New Century. Washington, DC: The National Academies Press, 2004.

[3] American Society of Civil Engineers. Civil Engineering Body of Knowledge for the 21st Century: Preparing the Civil Engineer for the Future. Reston: Library of Congress Cataloging-in-Publication Data, 2008.

[4] J. F. Volkwein, L. R. Lattuca, P. T. Terenzini, L. C. Strauss, and J. Sukhbaatar, "Engineering Change: A Study of the Impact of C2000," Int J Engng Ed, vol. 20, no. 3, pp. 318-328, 2004.

[5] C. Baillie and L. Vanasupa, Eds., Navigating the Materials World: A Guide to Understanding Materials Behavior, Elsevier, 2003. ISBN: 978-0-12-073551-8.

[6] W. M. Jordan, "Incorporating Active Learning and Sustainable Engineering Concepts into a Required Materials Class," in Proc. 2018 ASEE Annual Conference \& Exposition, Salt Lake City, UT, June 2018.

[7] L. Vanasupa, K.C. Chen, and L. Slivovsky, "Global challenges as inspiration: A classroom strategy to foster social responsibility," Science and Engineering Ethics, vol. 12, no. 2, pp. 373-380, 2006.

[8] R. Savage, L. Vanasupa, and J. Stolk, "Collaborative Design of Project-based Learning Courses: How to Implement a Mode of Learning that Effectively Builds Skills for the Global Engineer," in Proc. 2007 ASEE Annual Conference \& Exposition, Honolulu, HI, June 2007.

[9] K. C. Chen, "Materials Engineering with a Social Context: A Course on Materials, Ethics, \& Society", Materials Research Society (MRS) Online Proceedings Library, vol. 1532 (Symposium ZZ - Communicating Social Relevancy in Materials Science and Engineering Education), 2013, https://doi.org/10.1557/opl.2013.428

[10] ABET, "Accreditation criteria and supporting documents," Available: https://www.abet.org/accreditation/accreditation-criteria/ [Accessed February 3, 2019]

[11] J. A. Mejia, D. Chen, O. Dalrymple, and S. M. Lord, "Revealing the Invisible: Conversations about -Isms and Power Relations in Engineering Courses," in Proc. of the ASEE Annual Conference \& Exposition, Salt Lake City, UT, June 2018.

[12] G. D. Hoople and A. Choi-Fitzpatrick, "Engineering Empathy: A Multidisciplinary Approach Combining Engineering, Peace Studies, and New Technology," in Proc. of the ASEE Annual Conference \& Exposition, Columbus, OH, June 2017. 
[13] E. Reddy, G. D. Hoople, A. Choi-Fitzpatrick, and M. M. Camacho, "Engineering Peace: Investigating Multidisciplinary and Interdisciplinary Effects in a Team-Based Course About Drones", in Proc. of the ASEE Annual Conference \& Exposition, Salt Lake City, UT, June 2018.

[14] G. Hoople, A. Choi-Fitzpatrick, and E. Reddy, "Educating Changemakers: Cross Disciplinary Collaboration Between a School of Engineering and a School of Peace," in Proc. of the Frontiers in Education (FIE) Conference Proceedings, San Jose, CA, October 2018.

[15] B. Przestrzelski, E. Reddy, and S. M. Lord, "Integrating Social with Technical: "Bring in your Trash" module for a Materials Science Class," in Proc. of the ASEE Annual Conference \& Exposition, Salt Lake City, UT, June 2018.

[16] B. Przestrzelski, E. Reddy, and S. M. Lord, "Mission Possible: Blending the social and technical through an innovative biodesign challenge module for a materials science class," in Proc. of the Frontiers in Education (FIE) Conference Proceedings, San Jose, CA, October 2018.

[17] S. M. Lord, G. Hoople, J. A. Mejia, D. Chen, O. Dalrymple, E. Reddy, and B. Przestrzelski, "Creative Curriculum for Changemaking Engineers," in Proc. of the World Engineering Education Forum (WEEF) - GEDC Conference, Albuquerque, NM, November 2018.

[18] E. Reddy, B. Przestrzelski, S. M. Lord, and I. Khalil, "Introducing Social Relevance and Global Context into the Introduction to Heat Transfer Course," in ASEE Annual Conference \& Exposition, Salt Lake City, UT, June 2018.

[19] S.M. Lord, E. Reddy, and B. Przestrzelski, "Teaching Social Responsibility: Conflict Minerals Module for a Circuits Class," in Proc. of the World Engineering Education Forum (WEEF) - GEDC Conference, Albuquerque, NM, November 2018.

[20] D. Hoornweg and P. Bhada-Tata, "What a Waste: A Global Review of Solid Waste Management," World Bank, Urban Development and Local Government Unit of the Sustainable Development Network. Washington, DC, March 2012, no. 15.

[21] EDCO Disposal. San Diego. https://www.edcodisposal.com/san-diego/ [Accessed February 3, 2019]

[22] Waste for Life. http://www.wasteforlife.org [Accessed February 3, 2019]

[23] S. Bolduc, K.Jung, P. Venkata, M. Ashokcline, R. Jayasinghe, C. Baillie, and L. Lessard, "Banana fiber/low-density polyethylene recycled composites for third world eco-friendly construction applications-Waste for life project Sri Lanka," Journal of Reinforced Plastics and Composites, vol. 37, no. 21, pp. 1322-1331, 2018.

[24] Educational Materials Order Form. National Association for PET Container Resources (NAPCOR). https://napcor.com/napcor-education-material-order/ [Accessed February 3, 2019] 


\section{Appendices}

Module 1: Bring in Your Trash Worksheet Packet (to be read horizontally, where worksheet 3 and 4 are repeated to show that this individual worksheet was repeated several times in the packet)
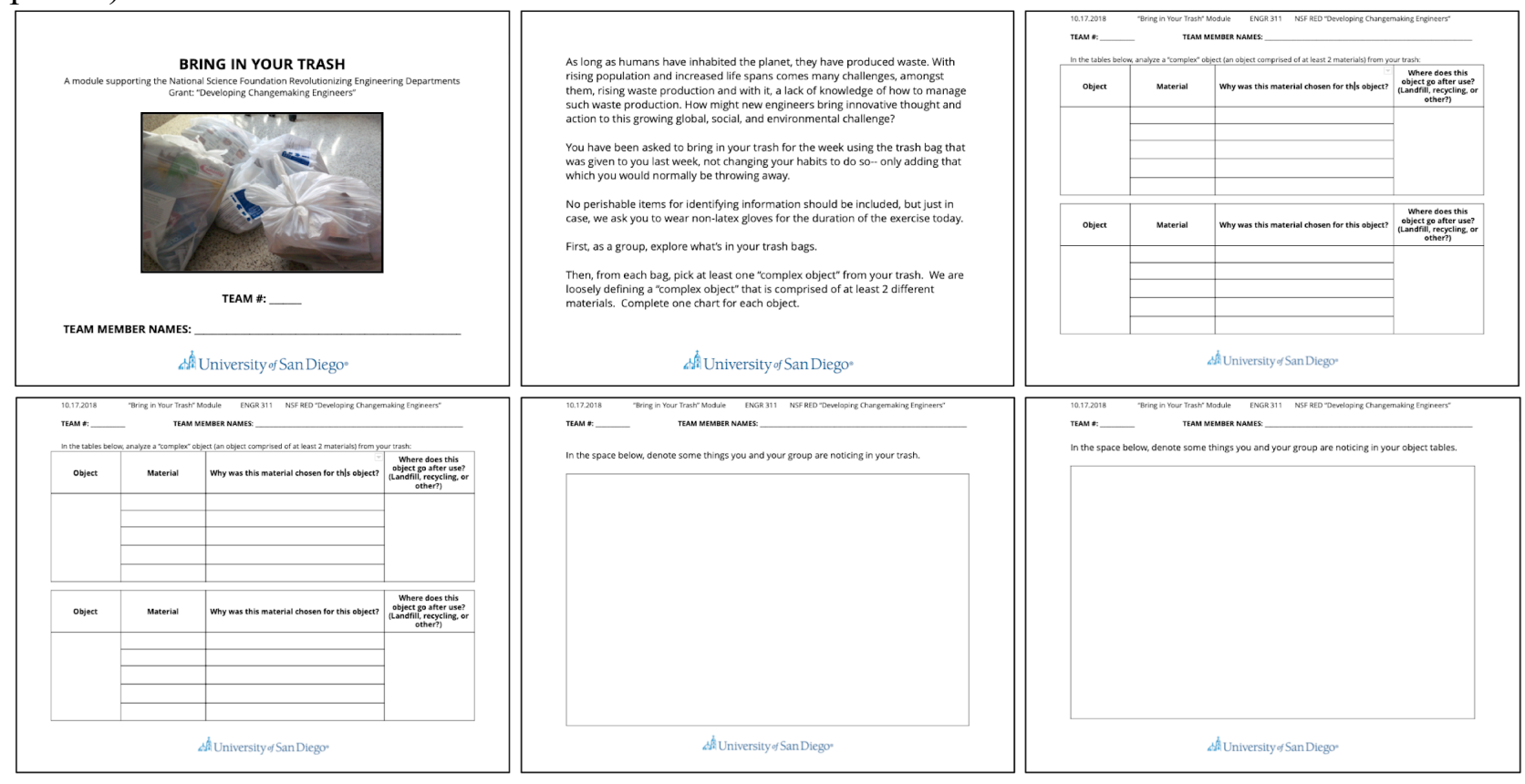

Module 4: Responsible Material Design Consultation Agreement/Assignment (Soda Lime Glass)

\begin{tabular}{|c|c|}
\hline \multirow{9}{*}{ 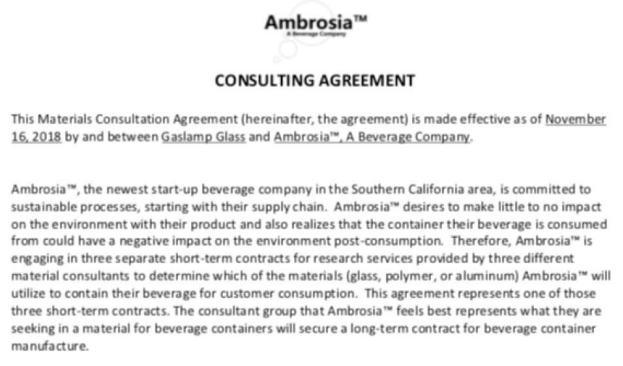 } & Ambrosia"w \\
\hline & III. SCOPE OF RESEARCH SERUCES \\
\hline & 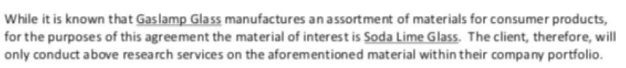 \\
\hline & IV. DESCRIPTIONS OF USED RESOURCES \\
\hline & 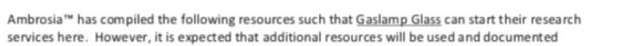 \\
\hline & \multirow{2}{*}{ 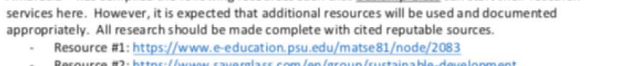 } \\
\hline & \\
\hline & 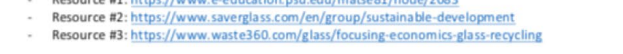 \\
\hline & COMMitMent Of PARTIES \\
\hline The above parties agree to the following terms and conditions: & \multirow[t]{2}{*}{ By signing below, all parties commit to the above terms and conditions of the agreement. } \\
\hline \multirow{5}{*}{ 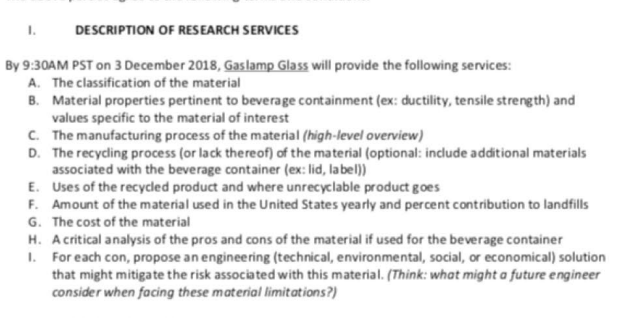 } & \\
\hline & $\overline{\text { Party } 41 \text { print }} \overline{\text { Date }}$ \\
\hline & Party \#1 Signature \\
\hline & \multirow[b]{2}{*}{ Party \#2 Member a1 Signature } \\
\hline & \\
\hline \multirow{4}{*}{ 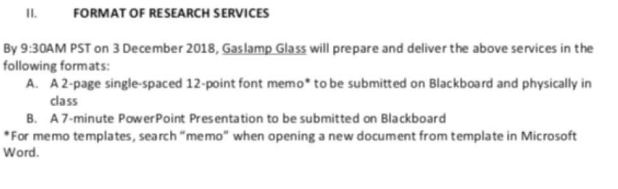 } & Party 12 Member i2 Print \\
\hline & Party \#2 Member \#2 Signature \\
\hline & Party \#2 Member \#3 Print \\
\hline & Party \#2 Member \#3 3 Signature \\
\hline
\end{tabular}


Module 4: Responsible Material Design Consultation Agreement/Assignment (PETE)

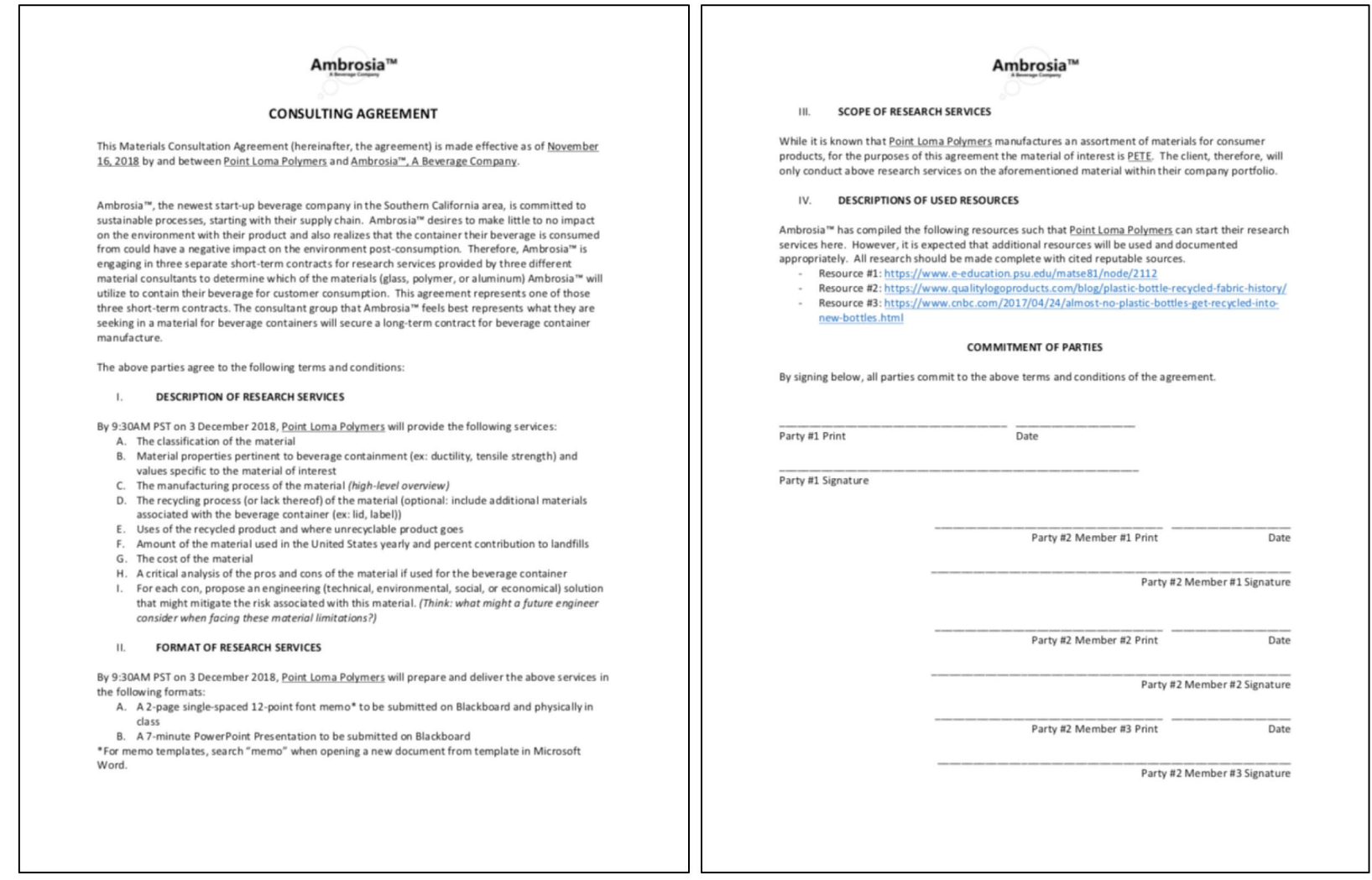

Module 4: Responsible Material Design Consultation Agreement/Assignment (Aluminum)

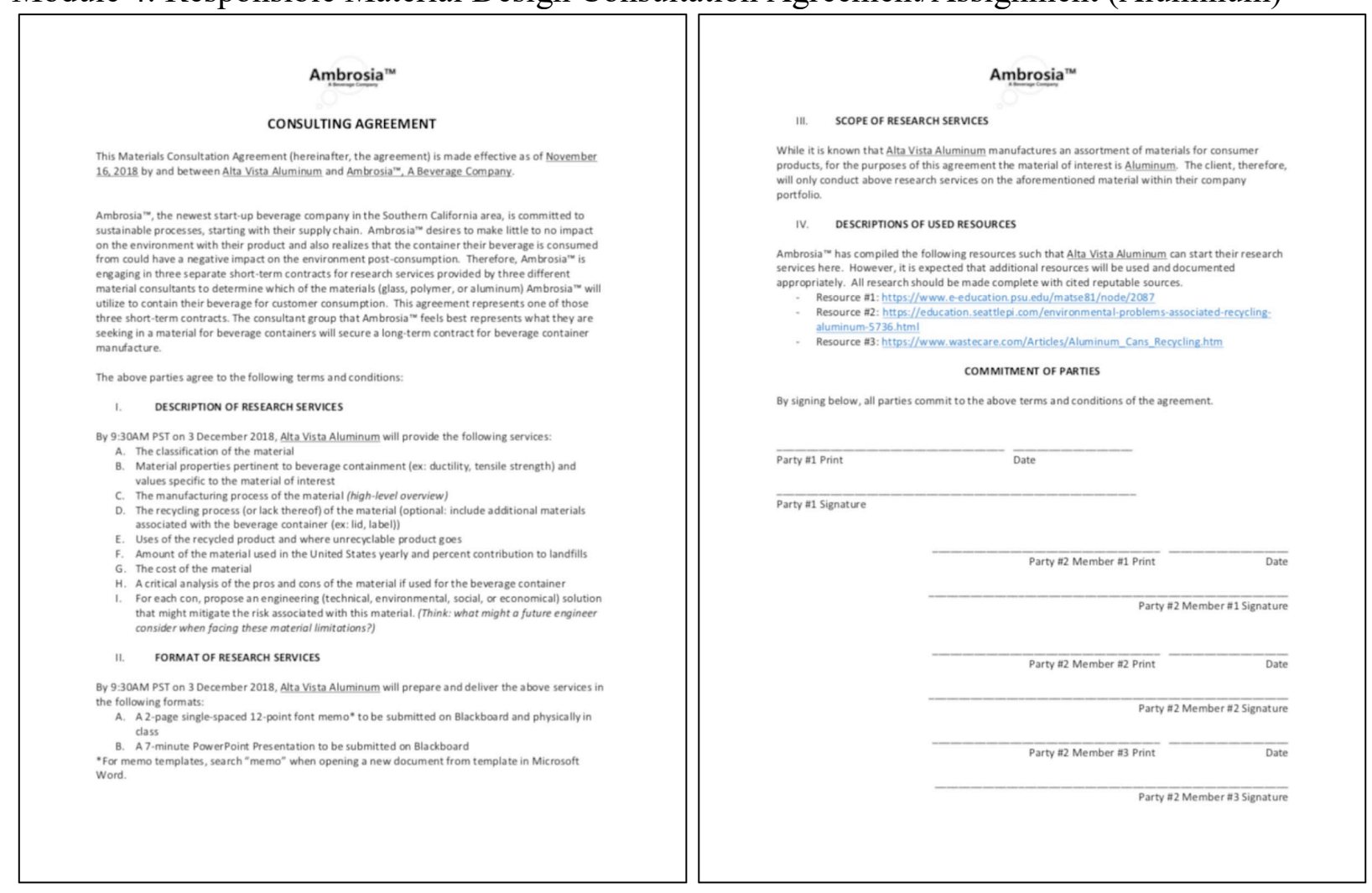

